\title{
Pricing Policy in an Integrated Two-echelon Supply Chain under Permissible Delay of Payment
}

\author{
Subhankar Adhikari
}

\begin{abstract}
This work examines the effect of pricing strategy in a supply chain consists of two members namely supplier and retailer. The supplier provides a credit period to the retailer. The retailer also provides a trade credit period to the customer within cycle length. A collaborative approach between two members is considered. The ultimate objective is to find maximum profit for the integrated system.
\end{abstract}

Keywords: Supply chain, two-stage, trade credit, price-sensitive demand, collaborative approach

\section{INTRODUCTION}

Now- a -days supply chain has absorbed a great deal of interest among researchers and practitioners. The impact of a supply chain in our daily life is enormous. In fact supply chain is characterized by various issues. The pricing issue associated with the context of the supply chain is very important. Demand is an essential component not only in the inventory but also in the supply chain. In many situations, demand is dependent on selling price. Generally, the relation between the selling price and the demand rate is inverse. As the selling price increases demand decreases. What will be the selling price of a product is a necessary question. Another issue that is very familiar in the supply chain is the trade credit issue. To attract retailers, the supplier offers trade credit while the situation is the same for the retailer when he offers credit period to customers. This research work formulates a mathematical model for the supply chain incorporating pricing strategy and trade credit issues.

\section{LITERATURE SURVEY}

Goyal [1] was the first to introduce the concept of trade credit in mathematical modeling. Then Abad and Jaggi [2] investigated the effect of co-operative and non-cooperative approaches between seller and buyer under permissible delay in payment atmosphere. Then Jaggi et al. [3] developed their work with credit period dependent demand pattern. Pal et al. [4] considered competition among retailers with a common supplier depending on a demand pattern based on price as well as credit period.

Mandal et al. [5] formulated an unreliable production system along with two-level credit policies. Bhunia et al. [6] considered partial backlogging incidents under the permissible delay of payment scenario. Bhunia and Shaikh [7] formulated different policies for deteriorating items.

Manuscript revised on July 5, 2021 and published on July 10, 2021 Subhankar Adhikari, Department Of Mathematics, Chandernagore College, Chandernagore, Hooghly, West Bengal, Pin-712136
Effects of inflation were incorporated by Tiwary et al. [8] In another work, Tiwary et al. [9] included the event of expiration dates under a partial trade credit environment. A single-stage model with quality dependent demand rate was studied by Pal et al. [10]. Giri and Sharma [11] developed two-level trade credits under a cash discount environment. Price-sensitive demand patterns under credit financing were developed by Giri et al. [12]. Effects of learning curves under two-stream credit financing were discussed by Feng and Chan [13]. Noteworthy works of Sarkar et al. [14], Xu, and Fang [15] in this direction have to be mentioned.

\section{BASIC ASSUMPTIONS WITH NOTATIONS}

- A supply chain consists of supplier and retailer

- Supplier offers a trade credit period $S$ to the retailer

- $T$ represents cycle length of the retailer

- $\quad$ The retailer offers a trade-credit period $R$ to the customer. Offered credit period $R$ is less than $T$. He sells the product at time $t(0<t \leq T)$ and get paid at the time $t+R$. The last payment is received at time $T+R$.

- $\quad$ The purchase price for supplier is $w$ per unit

- The purchase price for Retailer is $p$ per unit

- The purchase price for the customer is $s$ per unit

- The demand rate for the product is $D$. It is a monotonic decreasing function of the selling $\operatorname{price}(s)$. Here $D=a-b s$ where $a$ and $b$ both are positive.

- $I_{C}$ represents interest rate charged for both of the member's supplier and retailer

- $I_{E}$ represents interest rate earned by the retailer from the customer

\section{MODEL FORMULATION}

It is to be noted that offered credit period of retailer $R$. is less than the cycle length $T$. Now possible relations between $R$ and $S$ are either $R \leq S$ or $R>S$. Also, we have to keep in mind the fact that the retailer receives the last payment at the time $T+R$. Possible three Cases are given below

Case (a): $R \leq S<T<T+R$

Case (b): $R<T<T+R<S$

Case (c): $S<R<T<T+R$

First, we formulate a profit function from the retailer's end. Then we study the same thing from the supplier end. 
From retailer's point of view

Case (a): $R \leq S<T<T+R$

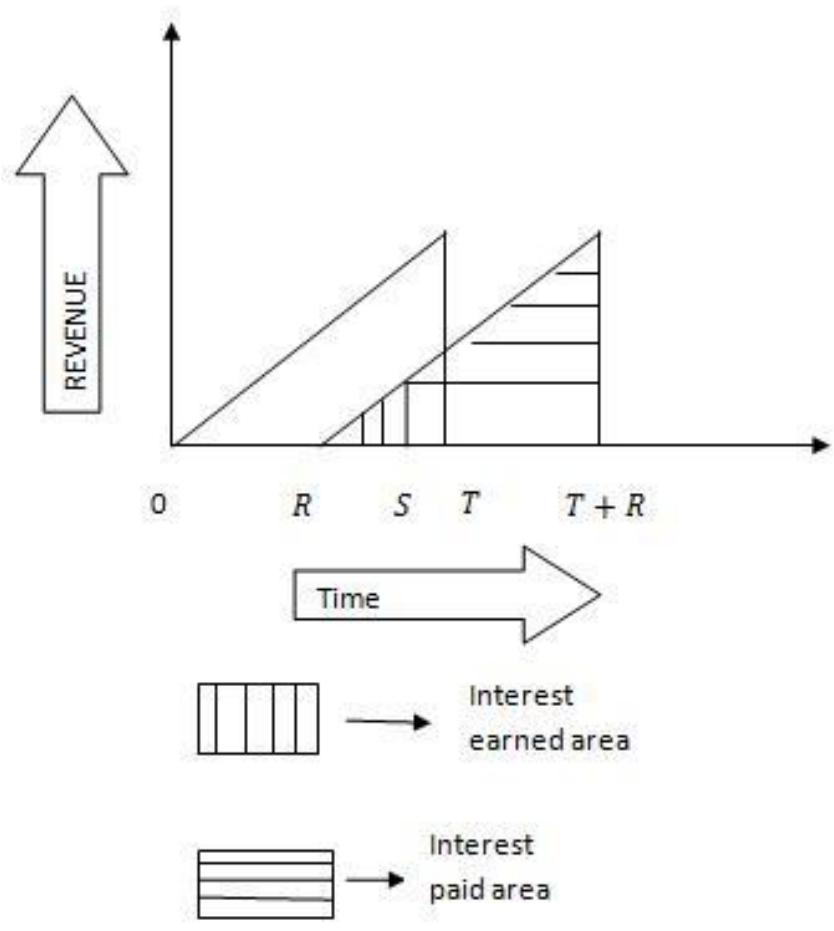

Fig 1: Revenue versus time for Case (a)

Retailer obtains interest from customer for the period $[R, S]$ and paid supplier interest for the period $[S, T+R]$ Interest earned by the retailer

$=\frac{1}{2} S I_{E} D(S-R)^{2}$

Interest paid by Retailer to the Supplier

$=\frac{1}{2} I_{C} p D(T+R-S)^{2}$

Sells revenue enjoyed by retailer

$=D T(s-p)$

Retailer's profit in this Case per unit time

$\pi_{R_{1}}=\frac{1}{T}\left[\begin{array}{c}D T(s-p)+\frac{1}{2} s I_{E} D(S-R)^{2} \\ -\frac{1}{2} I_{C} p D(T+R-S)^{2}\end{array}\right]$

Case (b): $R<T<T+R<S$

In this case, the retailer enjoys interest for the period $[R, S]$ and there is no possibility of paying interest to the supplier (see Figure 2)

Interest earned by the retailer

$=S I_{E} D T\left\{\frac{1}{2} D T^{2}+D T(S-T-R)\right\}$

$=S I_{E} D T\left(S-R-\frac{T}{2}\right)$

Sells revenue enjoyed by retailer

$=D T(s-p)$

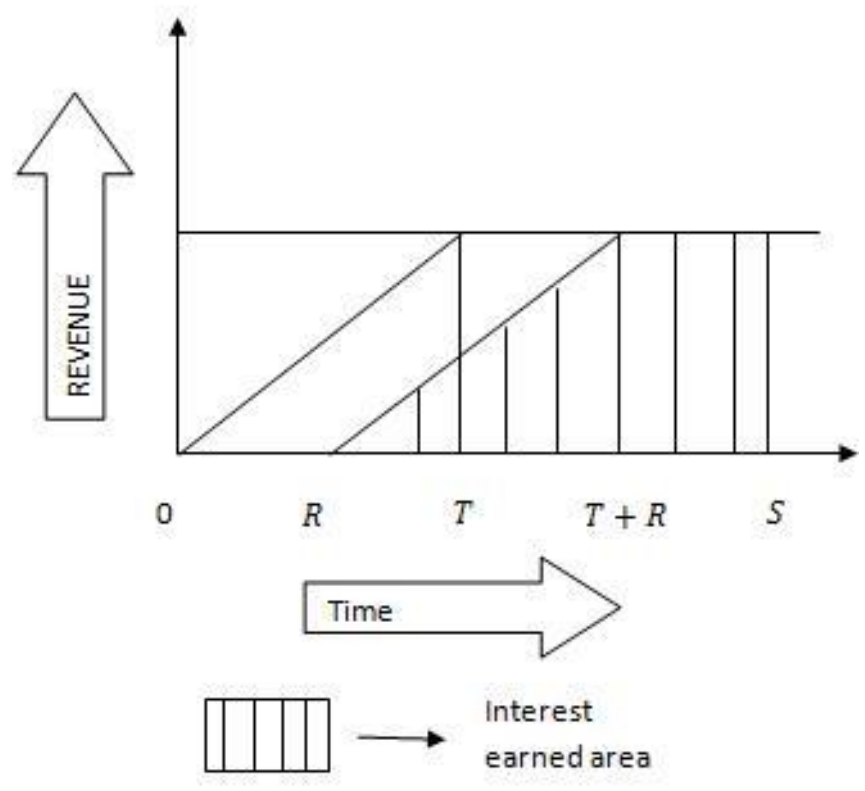

Fig 2: Revenue versus time for Case (b)

Retailer's profit in this Case per unit time

$\pi_{R_{2}}=\frac{1}{T}\left[D T(s-p)+s I_{E} D T\left(S-R-\frac{T}{2}\right)\right]$

Case (c): $S<R<T<T+R$

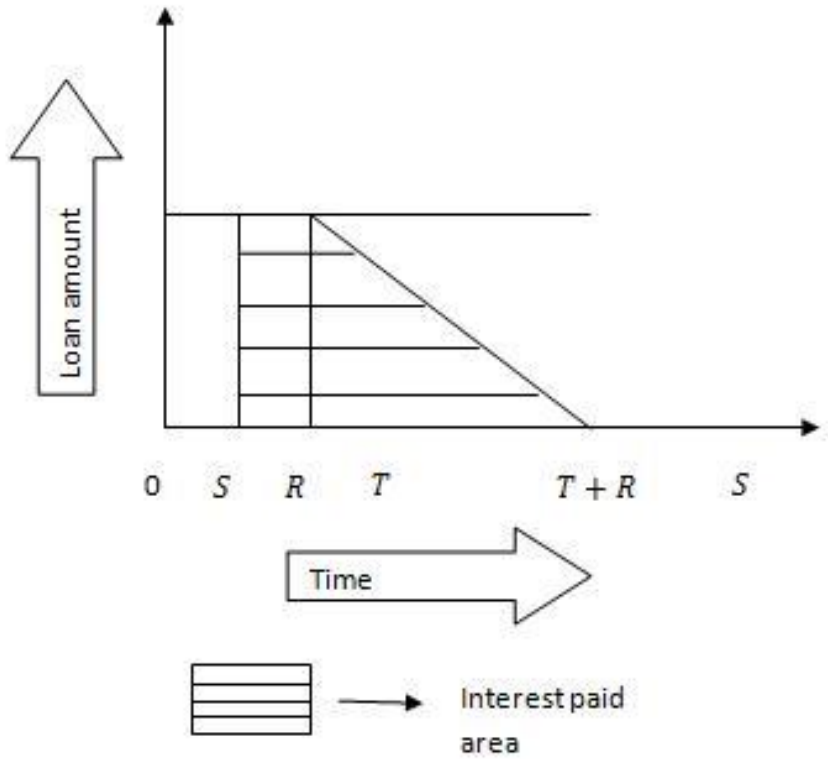

Fig 3: Loan amount versus time for Case (c)

In this case retailer's interest paid amount to the supplier is measured by calculating the reduction of the loan amount. The retailer has to pay interest for the full amount $D T$ for the time period $[S, R]$. Then loan amount of the retailer reduces as he gets revenue from the customer.

Interest paid by the retailer

$=p I_{C}\left[D T(R-S)+\frac{1}{2} D T^{2}\right]$

$=p I_{C} D T\left(R-S+\frac{T}{2}\right)$ 


\section{Available online at www.ijrat.org}

In this Case retailer's profit per unit time

$$
\pi_{R_{3}}=\frac{1}{T}\left[D T(s-p)-p I_{C} D T\left(R-S+\frac{T}{2}\right)\right]
$$

Now we formulate a profit function for the supplier.

As the supplier gives a credit period $S$ then he has to bear some interest. His loss of interest for two situations are given below

$$
=\left\{\begin{array}{c}
\frac{1}{2} D S^{2} I_{C} w \text { when } S<T \\
D T I_{C} w\left(S-\frac{T}{2}\right) \quad \text { when } S \geq T
\end{array}\right.
$$

Revenue obtained by the supplier for selling quantity to the retailer is $=D T(p-w)$.

If supplier's profit for Cases (a), Case (b), and Case (c) are denoted by $\pi_{S_{1}}, \pi_{s_{2}}$ and $\pi_{S_{3}}$ respectively then they are as follows

$$
\begin{aligned}
& \pi_{S_{1}}=\frac{1}{T}\left[\begin{array}{c}
D T(p-w)-\frac{1}{2} D S^{2} I_{C} w \\
+\frac{1}{2} I_{C} p D(T+R-S)^{2}
\end{array}\right] \\
& \pi_{S_{2}}=\frac{1}{T}\left[D T(p-w)-D T I_{C} w\left(S-\frac{T}{2}\right)\right] \\
& \pi_{S_{3}}=\frac{1}{T}\left[\begin{array}{c}
D T(p-w)-\frac{1}{2} D S^{2} I_{C} w \\
+p I_{C} D T\left(R-S+\frac{T}{2}\right)
\end{array}\right]
\end{aligned}
$$

\section{SOLUTION Procedure}

Here both supplier and retailer take decisions jointly. This approach is known as the collaborative approach. The profit of the integrated system is determined by both members' profit functions. If $\pi_{1}, \pi_{2}$ and $\pi_{3}$ represent profit functions for Case (a), Case (b), and case (c) respectively, then they are

$\pi_{1}=\pi_{s_{1}}+\pi_{R_{1}}, \pi_{2}=\pi_{s_{2}}+\pi_{R_{2}}, \pi_{3}=\pi_{s_{3}}+\pi_{R_{3}}$ Using relations (1), (2), (3), (4), (5), and (6) we get an expression of profit functions

for Case (a): $R \leq S<T<T+R$

$\pi_{1}=D(s-w)+\frac{1}{2 T} s I_{E} D(S-R)^{2}-\frac{1}{2 T} D S^{2} I_{C} w$

for Case (b): $R<T<T+R<S$

$\pi_{2}=D(s-w)+s I_{E} D\left(S-R-\frac{T}{2}\right)-D I_{C} w\left(S-\frac{T}{2}\right)$

For Case (c): $S<R<T<T+R$,

$$
\pi_{3}=D(s-w)-\frac{1}{2 T} D S^{2} I_{C} w
$$

We aim to maximize profit for the integrated system. It would be possible if $\frac{d^{2} \pi_{i}}{d s^{2}}<0$ for $i=1,2,3$

From (7) differentiating $\pi_{1}$ twice concerning $s$, we have

$\frac{d^{2} \pi_{1}}{d s^{2}}=-2 b-\frac{1}{T} b I_{E}(S-R)^{2}$

$=>\frac{d^{2} \pi_{1}}{d s^{2}}<0$ since $b, T, I_{E}$ all are positive

Similarly from (8), we have

$\frac{d^{2} \pi_{2}}{d s^{2}}=-2 b-2 b\left(S-R-\frac{T}{2}\right)$
In this case, $T+R<S$. This implies $S-R>T$. So $S-R>\frac{T}{2}$ also.

We have $\frac{d^{2} \pi_{2}}{d s^{2}}<0$

Differentiating relation (9) twice with respect to $s$, we get $\frac{d^{2} \pi_{3}}{d s^{2}}=-2 b$.Clearly $\frac{d^{2} \pi_{3}}{d s^{2}}<0$

So profit functions for variable ranges of time are maximized.

\section{Conclusion}

Trade credit policy is a very common thing in the business world. Here two-level trade credit policies are considered. For the different duration of the credit period, different Cases come up. Profit functions associated with each case are formulated. It is maximized analytically.

\section{FutURE DIRECTION OF RESEARCH}

There are many options regarding the extension of this model. Partial trade credit policies among the members can be framed based on this work. Thinking of deteriorating items would be another way of extending this work. If shortages are allowed then must be backlogged either completely or partially. Various types of partial backlogging ensure a new extension of this work.

\section{REFERENCES}

[1] S. K. Goyal, "Economic Order Quantity Under Conditions of Permissible delay in payments", Journal of the Operational Research Society, vol. 36 , no.4, pp.335-338,1985.

[2] P. L. Abad and C. K. Jaggi, “ A joint approach for selling unit price and the length of the credit period for a seller when end demand is price sensitive", International Journal of Production Economics, vol.38, pp. $115-122,2003$

[3] C. K. Jaggi, S.K. Goyal, S. K . Goel, "Retailer's optimal replenishment decisions with credit link demand under permissible delay in payments", European Journal of Operational Research, vol no.190, pp. $130-135,2008$

[4] B. Pal, S. S. Sana, K.S. Chaudhuri, " Two-echelon competitive integrated supply chain model with price and credit period dependent demand", International Journal of System Science, vol.45, no.9, pp.1844-1868, 2014.

[5] A. Mandal, B. Pal, K. S. Chaudhuri, "Unreliable EPQ model with variable demand under two-tier credit financing", Journal of Industrial and Production Engineering, vol.37, no.7, pp.370-386, 2020.

[6] A.K. Bhunia, C. K. Jaggi, A. Sharma, R. Sharma, “ A two-ware house inventory model for deteriorating items under permissible delay in payment with partial backlogging", Applied Mathematics and Computation, vol.232, pp 1125-1137, 2014.

[7] A.K. Bhunia, A. A. Shaikh, "An application of PSO in a two-ware house inventory model for deteriorating item under permissible delay in payment with different inventory policies", Applied Mathematics and Computation, vol.256, pp 831-850, 2015

[8] S. Tiwary, L.E. Cardenas Barron, A Khanna, C.K. Jaggi, " Impact of trade credit and inflation on retailer's ordering policies for non-instantaneous deteriorating items in a two-warehouse environment", International Journal of Production Economics, vol.176, pp. 154-169, 2016.

[9] S. Tiwary, L.E. Cardenas Barron, M. Goh, A. A . Shaikh, “ Joint pricing and inventory model for deteriorating items with expiration dates and partial backlogging under two-level partial trade credits in the supply chain", International Journal of Production Economics, vol. 200, pp. 16-36, 2018

[10] B. Pal, "Optimal production model with quality sensitive market demand, partial backlogging and permissible delay in payment", RAIRO-Operations Research, vol. 52, no.2, pp. 499-512,2018. 
[11] B. C. Giri, S. Sharma, "Optimizing an integrated production-inventory system under cash discount and retailer partial trade credit policy", International Journal of System Science: Operations and Logistics, vol.6, no.2, pp.99-118,2019.

[12] B. C. Giri, R. Bhattacharjee, T. Maity, " Optimal payment time in a two-echelon supply chain with price dependent demand under trade credit financing", International Journal of System Science: Operations and Logistics, vol.5, no.4, pp.374-392,2018.

[13] L. Feng, Y-L Chan, “ Joint pricing and production decisions for new products with learning curve effects under up-stream and down-stream trade credits", European Journal of Operational Research, vol.272, no.3, pp.905-913,2018.

[14] B. Sarkar, B. K. Dey, M. Sarkar, S. Hur, B. Mandal, V. Dhaka, “ Optimal replenishment decision for retailers with variable demand for deteriorating products under a trade-credit policy", RAIRO-Operations Research, vol.54, no.6, pp.1685-1701,2020.

[15] S. Xu, L. Fang, "Partial credit guarantee and trade credit in an emission-dependent supply chain with capital constraint",
Transportation Research Part E, vol.135, article no.101859, pp.1-29, 2020 .

\section{AUTHORS PROFILE}

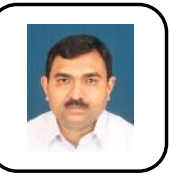

Subhankar Adhikari is an Assistant Professor In Mathematics Of Chandernagore College. He has obtained an M.SC degree in Mathematics from Jadavpur University, Kolkata. He has published papers in the International Journal of System Science: Operations and Logistics, RAIRO-Operations Research, International Journal of Mathematics in Operational Research. His research area includes an inventory system and supply chain management. 